\title{
Bridging the Curriculum Divide: A Proposal for Expressive Writing in World Language Content Courses
}

\author{
Elizabeth C. Langley \\ Modern Languages, Fort Hays State University, Hays, United States
}

\begin{abstract}
In 2007, the Modern Language Association (MLA) called for significant changes to world language programs due to a curricular bifurcation between basic language courses and upper-division content courses. Although significant inroads have been made in the last 14 years, the two-tiered curriculum structure still exists in many programs, and the urgency for curricular coherence has been heightened by a dwindling number of language majors coupled with institutional disinvestment in language departments. In practice, when language programs have not undergone a significant redesign, the general remedy for this divide is to include more authentic content in the target language in lower-level courses and to provide opportunities to continue to develop the full range of linguistic skills in upper-level content courses. In this proposal, I enter the conversation surrounding the curriculum divide in language programs and recommend a supplementary approach to previous solutions. I explore the advantages and disadvantages of expressive writing in advanced language courses and propose that including expressive writing assignments in world language content courses will help bridge the divide between lower-level and upper-level curricula. More specifically, I argue that expressive writing encourages students to continue to develop their voice from lower-level courses, to activate their background knowledge and facilitate reflection on course content, and to develop their linguistic skills in lower-stakes writing assignments. I also offer suggestions for adaptable, expressive assignment types for advanced language content courses.
\end{abstract}

Index Terms - expressive writing, world languages, content courses, curriculum divide

\section{INTRODUCTION}

In world language study in the United States, there is traditionally a divide in focus between basic language courses (beginning to lower-intermediate levels) and upper-division content courses, where the former focuses on developing linguistic skills (speaking, listening, reading, and writing) ${ }^{1}$ at the expense of examining content, and the latter explores content, including literature, film, and cultural studies; linguistics; and world languages for the professions, ${ }^{2}$ with limited focus on continuing to hone linguistic skills. According to Kate Paesani and Heather Willis Allen (2012), this is a "long-standing and well-documented bifurcation" (p. S55). Further complicating this matter is a significant downturn in the number of students pursuing world language coursework beyond the intermediate level despite a renewed interest in lower-level language study and government investment in world language programs following the wars in Afghanistan and Iraq. Disinvestments by universities in language programs, reducing or limiting language requirements, as well as a more general downturn in humanities majors are contributing factors (Flaherty, 2018). The urgency, then, of reinvigorating the curriculum for twenty-first century students remains apparent. The 2007 Modern Languages Association (MLA) inquiry into this question advocated for "replacing the two-tiered language-literature structure with a broader and more coherent curriculum in which language, culture, and literature are taught as a continuous whole" (Geisler, 2007, p. 236). In practice, when programs have not been completely redesigned, the general remedy for this divide is to include more authentic content or realia in the target language in lower-level courses and to provide opportunities to continue to develop the full range of linguistic skills along with provide relevant feedback to students in upper-level content courses.

Furthermore, the curricula of basic language classes tend to focus on expressive writing (and speaking) because the topics of study often revolve around student habits, preferences, and experiences with respect to topics like classes, family, food, hobbies, and clothing. Writing assignments often shift dramatically once students reach content classes, where literary analysis and research essays become the most common type of writing. In this essay, I will explore the advantages and disadvantages of expressive writing in advanced language courses and propose that including

\footnotetext{
${ }^{1}$ The common alternative to a skills-based focus in world language courses revolves around three modes of communication: the presentational, interpersonal, and interpretive.

${ }^{2}$ In the case of world language courses for the professions, there is a potential for overstatement about this divide. That is, this type of course can vary in terms of its content where some are essentially literature and culture courses with a theme related to a profession such as illness in literature (medical field) or business in different forms of cultural production. Other courses may be more oriented toward teaching vocabulary and developing conversational skills in a professional context. In the case of the latter, the question of the divide or two-tiered system may be less notable.
} 
expressive writing assignments in world language content courses will help bridge the divide between lower-level and upper-level curricula. More specifically, it will encourage students to continue to develop their voice from lower-level courses, activate background knowledge, and facilitate reflection on course content, as well as develop their linguistic skills in lower-stakes writing assignments. In addition, I will offer suggestions for adaptable, expressive assignment types for advanced language content courses.

\section{EXPRESSIVE Writing AND ITS TyPiCAL Role IN THE World LANGUAGE ClassRoom}

Before delving into the role expressive writing can play in the world language classroom, it is important to establish what it is. Expressive writing is writing that focuses on the self, the personal, or features the "I." It is recursive, and it can be process-oriented and collaborative. Expressive writing is useful for brainstorming, working through ideas, recalling something, or reflecting. Notes, letters, and journals are just a few examples of genres that could fall under the umbrella of expressive writing. In terms of pedagogy, it allows students to develop a voice, it can be motivating and empowering because it is student-centered, and it places the onus of writing on the student. Expressive pedagogy also "fosters a writer's aesthetic, cognitive, and moral development" (Burnham and Powell, 2014, p. 113). In the classroom, in addition to writing, expressive pedagogy means creating opportunities for dialogue and adding a social dimension to writing or developing one's own voice within a community. Gary R. Cobine (1996) argues that expressive writing "is potentially a vehicle for learning, in general, and for learning to write, in particular" (p. 3). That is, this property of expressive writing foregrounds the educational because it affords students the freedom to work out ideas as they write.

Expressive writing is relatively common in the lower-division world language classroom. Students often write minicompositions describing themselves, their interests, and habits. Although perhaps more utilized in high school than college, assigning daily or weekly journals in the target language either on an umbrella topic or open topic, is another frequent form of expressive writing in the basic language classroom. An increasingly deployed writing form in comprehensible input (CI) classrooms - a form of second language pedagogy based on Stephen Krashen's i+1 concept or the idea that moving to a higher stage of language acquisition involves being exposed to and understanding input in the target language just beyond one's level of comprehension (Krashen, 1982) — is freewriting, especially once students have been exposed to frequent input for several weeks if not months. Freewriting allows students to simply write for a period of time on a topic with significant freedom. It is worth noting that although this iteration of CI is becoming more important in the university classroom, high school teachers are more likely to use this teaching method at present. Beyond expressive writing, students may also begin writing persuasive essays and complete short research-based reports in basic language courses, especially at the lower intermediate level.

In upper-division courses, however, expressive writing is not particularly common with the possible exception of composition courses that may promote writing across several types of genres. The other possible exception is the use of discussion boards and blog posts, which may vary in levels of formality or promotion of developing a voice, where students respond to course materials in some upper-division courses. At the lower level, this type of writing tends to be more common in online or hybrid courses. Community-based learning courses and practice-oriented translating courses - course types that are still relatively uncommon in university language programs - may also involve reflective writing. Upper-division literature and cultural courses, which still make up the core of upper-division curriculum in most university language programs, usually require literary close readings (explications de texte) and research essays and minimal expressive writing.

\section{The CASE FOR EXPRESSIVE Writing IN CONTENT COURSES: AdVANTAGES AND DisAdvant AGES}

Despite some improvements in course integration since the MLA report in 2007, this difference in terms of writing expectations and pedagogical approach at different levels of the curriculum appears to be constitutive of the bifurcation between course types and levels. To help mend this gap, I would propose implementing expressive writing assignments in upper-division courses. Students will be familiar with this genre from their basic language curriculum, and that will help ease the transition into content coursework. As content courses can require a period of adjustment for students, incorporating a familiar genre would reduce the level of adjustment. Additionally, depending on the parameters of the assignment, expressive writing would likely allow students to activate their background knowledge on a topic, which will help lower their affective filter or anxiety level, and help prepare them to contribute to the class discussion in the target language. Furthermore, expressive writing also increases student motivation and potential for empowerment. This is key because motivation is a determining factor for students to make proficiency gains when learning another language. Numerous studies also suggest that expressive writing can be beneficial to health and well-being. In a study of bilingual students, for example, Youngsuk Kim (2008) found that there were social and psychological benefits for bilinguals who wrote expressively, with the most interesting outcome being that bilingual students who alternated between languages in their expressive writing (i.e., writing in one language one day, the other language the next) reported the greatest social benefits among study participants (p. 46). Although the literature on expressive writing in the foreign or second language classroom is not extensive, I will highlight the findings of a few additional studies that point toward its efficacy. 
In "An Inquiry into Expressive Writing: A Classroom-Based Study," Linda Bilton and Sivakumar Sivasubramaniam (2009) make a case for incorporating expressive writing into EFL/ESL (English as a Foreign Language / English as a Second Language) writing courses. Their plea arises out of what they deem "a current malaise" in EFL/ESL writing (p. 301). Their study featured a literature class where students were required to complete reader response activities where they would indicate whether or not they liked a text and explain why. The goal was to focus on their experience and expressing their thoughts rather than reading comprehension (p. 305). The researchers found that expressive writing was engaging and motivating for students, encouraged them to interrogate their place in the world, and promoted writing fluency and critical reading (pp. 315-316). The researchers did claim, however, that the expressive writing activities used generated a love for writing in the students. Specifically, they maintain that students eagerly attempted to personalize their writing. They posit that: "We do not believe that personalization of writing can happen in the absence of a love of writing" (p. 316). Although I generally agree with the authors when they go to great lengths to trouble the notion of rational, objective writing as the only or primary means of promoting second language acquisition through writing, this interpretation of the love of writing simply goes beyond the data. That is, personalizing writing alone does not necessarily mean students "loved" an assignment or writing more generally. This deficit of data could be amended by having students respond to the response activity (the object of study) or reflect on their experience during the activity in an evaluation to better determine how they felt about the writing assignments in the course. Despite this overstatement, this study points convincingly toward the effectiveness of expressive writing in the world language content course.

Additionally, Seyyed-Abdolhamid Mirhosseini and Roya Kianfar (2019) advocate for what they term wor(l)d writing in "Writing the World in a Foreign Language." For them, writing is as much about the writer as it is about the writing (p. 6). They break down the relationship between the word and the world in writing by noting and advocating for the relationship between the self and the social or the writer and their context. They also offer examples of writing they think exemplifies wor(l)d writing in which the writers reflect on their own experiences, relationships to different cultures, as well as orientations to education and/or academic writing. In both of these scholarly examples (Bilton and Sivasubramaniam; Mirhosseini and Kianfar), then, the writing centralizes the writer's voice and experience in relationship to the world around them. Mirhoseeini and Kianfar do, however, complicate the notion of wor(l)d writing in their text by thinking about academic writing and the way that it can hinder the expression of the self (p. 7). In the last section, they encourage academics to offer the included examples of wor(l)d writing as possibilities for students writing in an academic setting. They maintain that this would "welcome writing that has a hybrid character, comprising a combination of lives and languages as well as a combination of genres or styles (narrative and analysis)" (p. 10). Their final plea asks that teachers not remove structure and technical concerns in writing from their context because it should include the writer's world (p. 10). Although this article is framed in a somewhat unique way, it is advocating for expressive writing within a social context. In other words, expressive writing should be read, the writer should consider their context, and foreign language writing has the potential to expand the writer's worldview and the possibilities of their writing.

There are, however, some potential risks or disadvantages of expressive writing in the language classroom. One relates to time and number of assignments. Simply put, instructors are limited in the number of assignments or projects they can assign due to the length of the semester, what is reasonable for student workload, and the number of assignments instructors can grade in a meaningful way (i.e., provide feedback). Certainly, however, expressive writing does not have to be the only form of writing in a course, and expressive writing could be used as a kind of reading check to make sure that students are reading and thinking critically about material rather than assign expressive writing in lieu of a research paper. Another potential disadvantage is student orientation toward other types of writing that may be relevant in the course. More specifically, if a student can complete response writings in a literature course that intimate their preferences and opinions surrounding a text, an instructor may fear that this type of engagement will carry over in an academic essay or a formal close reading of a text. To mitigate this, instructors should clearly state their expectations for different writing assignments, offer rubrics or check sheets, include opportunities for feedback before deadlines for heavily weighted writing assignments, and offer examples of the genre where applicable. At the same time, it can be said that this kind of commentary around a text is relatively common in classroom discussion, so expressive writing should not necessarily generate an opinion-based essay any more often than classroom discussion does.

An initially concerning potential disadvantage of promoting expressive writing in a content course concerns identity and community belonging. That is, one criticism of expressive writing is that it may force students who belong to a collective identity to write from a point of view that feels manufactured or to create a new self (Burnham and Powell, 2014, p. 118). At the same time, the expressive classroom can still promote dialogic opportunities for students to engage with a student community, which may mitigate the notion of an isolated self who has been removed from a collective identity. Relatedly, Victor Villanueva (2004) has written about the relationship between writing, conjuring memory, and identity formation for writers of color in particular (p. 12). He calls for a renewed interest in memoria, which referred to memory or the memorization of speeches in traditional rhetoric. As this rhetorical feature has been largely sidelined as a focus in academic writing, Villanueva advocates for it and relates it to both individual and collective memory, or the shared memory of a group of people: 
And though Aristotle thought it not right to sway with emotional appeals, he knew that the greatest impact on listeners is in fact the emotional. The personal here does not negate the need for the academic; it complements, provides an essential element in the rhetorical triangle, an essential element in the intellect-cognition and affect. The personal done well is sensorial and intellectual, complete, knowledge known throughout mind and body, even if vicariously (p. 14).

The idea is that the personal can actually augment academic writing by adding an affective lens informed by experience rather than hinder its supposed objectivity. Therefore, even with more traditional academic writing like the research essay, the personal can reinvigorate the genre and be empowering, especially for writers of color. Arguably, this view of affect is all the more applicable in the second or world language classroom where many students may be heritage learners, especially in Spanish language study in the United States, who are seeking to connect with their identity and history through the study of the language and culture of their parents or forebears. Heritage learners may also identify as writers of color, and following Villanueva's point of view, expressive writing could benefit them in terms of empowerment and connection. Although heritage learners often come to a language class with significant prior linguistic knowledge and may be working to acquire a more formal register in their language, ${ }^{3}$ this can still be achieved through the kind of expressive writing Villanueva espouses, which is academic writing with a voice. Additionally, it is also typical for scholars focusing on postcolonial literature or the Global South to write using "I" and from a specific point of view that does little to obscure their voice. Although it would depend on the language, content, and constituency of a class, there are potential gains to an expressive infusion even in what is perceived as more academicoriented writing (e.g., research essay) in some world language content courses.

\section{EXPRESSIVE Writing IDEAS FOR CONTENT COURSES AND THEIR BENEFITS}

The options for expressive writing assignments in upper-division content courses are many. A simple approach to incorporating expressive writing is to have students complete response writing when reading, reflective writing in response to course materials, or to annotate course materials as a class. This can be completed in a journal, blog, or discussion board format, depending on the level of interaction or type of relationship the instructor wishes to establish through the writing and how it corresponds to class discussion. That is, depending on the parameters set, a journal would be more personal and potentially read by only the instructor or another student, a blog would likely be more open in terms of the audience who could access it, and a discussion board would be more interactive.

Because of the aesthetic nature of the content, response writing may be a particularly apt way to incorporate expressive writing in a literary or film studies course. The student could respond to a particular theme or event in a story and relate it to their own life or prior knowledge. In a course on sociolinguistics, a student could reflect on how they relate to a particular reading. For example, on a reading treating perceptions of accents or language attitudes, the student may be able to offer a personal experience based on their origin or a linguistic example based on their personal variety/ies of the language in question. In languages for specific purposes courses, such as Medical Spanish or Business French, reflective writing could be beneficial as well. Given that languages for the professions often supplements another course of study such as business or nursing, freewriting on course topics could be generative for class discussion because it would allow students to activate prior knowledge in the target language. Combining personal response or reflection with annotations could also be productive toward promoting expressive writing in upper-division content courses. This strategy may appear to be most effective for literature, but it could also be used for linguistics and languages for specific purposes courses. Using collaborative annotation with comments would also be a way of adding a dialogic, social element to the expressive assignment so that the personal is not removed from the community.

There are many other potentially effective options for reflective writing assignments in upper-division content courses, and changing the parameters, such as genre, audience, or expectations for responses can breathe new life into an assignment type - such as journal writing - and render it more responsive to particular course materials or prepare students for a potentially higher stakes assignment. When developing these types of expressive writing assignments for the world language classroom, I find Gary R. Cobine's (1996) recommendations to be particularly helpful. He maintains that instructors should allow students some freedom of topic in their writing assignments so that they can develop their ideas and voice (p. 9). At the same time, instructors should provide some direction, so that students do not feel lost and can find a point of departure. Instructors should aim to develop an "expressive relationship" with their students; this can be achieved through a dialogue journal or through "the teacher's non-judgmental response" to expressive assignments, such as freewriting (p. 9). Instructors should also encourage students to write rhetorically, thinking carefully about and highlighting their intended audience and the purpose of their writing, even for many expressive writing assignments.

\section{CONCLUSION}

\footnotetext{
${ }^{3}$ Certainly, the reasons that heritage learners pursue language study can vary. Additionally, heritage learners or heritage speakers enter language courses with a wide variety of proficiency levels and linguistic skillsets. Some are closer to balanced bilinguals, others are advanced speakers with limited writing proficiency, some can only understand spoken Spanish and feel inadequate with oral or written production, and others may have limited knowledge of more formal registers, whether in speaking or writing.
} 
The two-tiered curriculum system in university language departments has not been in the best interest of students and needs revision to ensure an integrated, engaging approach to language education. This modification would also likely have the added benefit of encouraging students to pursue further language study, which is important in a climate of reduced humanities majors more generally and the shuttering of many collegiate language programs in recent years. Other than full program revisions, the predominant method of remedying this situation has been to include more authentic content in the target language in basic language courses and to provide additional feedback on linguistic concerns in different modalities in content courses. Moving beyond these options, another promising way of bridging the basic language-content divide is through expressive writing. As I have pointed out, this would allow students to build on a genre of writing with which they have familiarity from their basic language coursework. It would also help students activate prior knowledge, allow them to continue to develop their writing skills in the target language in a low stakes fashion, and provide opportunities for them to interact with the course material in new ways. Expressive writing has the added benefit of promoting interaction and dialogue, which are fundamental in basic language classrooms, but have sometimes been stifled in upper-level content courses because of the nature of the language (e.g., early modern literature in another language) and prior knowledge barriers. It also provides students the opportunity to write to learn, to develop an expressive writing relationship with their peers and their instructor, and to develop their sense of self in relationship to the world (Mirhosseini and Kianfar's wor(l)d writing) in a language that may not be native to them.

Ultimately, expressive writing has the capacity for empowering, motivating, and healing. It furnishes the opportunity to connect to others with a shared identity and story. Considering the movement from European languages and literatures to world languages and literatures and the way that writing about the Global South has incorporated specific points of view, including expressive components in traditional academic writing assignments (and beyond) in the world language classroom may also be more inclusive and appropriate than traditional approaches. In a field concerned with intercultural communicative competence, the self and its relationship to the world should be elevated in assignments, especially in writing assignments where students have the time and wherewithal to reflect on their ideas and their language use. In short, language instructors should not neglect their students' development of an "I" or a yo, je, mwen, $e u$, or ich - to name just a few of the many non-English linguistic forms that "I" can take - in their writing and its relationship to the world.

\section{ACKNOWLEDGEMENTS}

The author wishes to thank Cheryl Duffy and Sarah Langley for their readership and feedback on prior drafts of this article.

\section{REFERENCES}

[1] Bilton, L., \& Sivasubramaniam, S. (2009). An Inquiry into Expressive Writing: A Classroom-based Study. Language Teaching Research: LTR, 13(3), 301-20.

[2] Burnham, C., \& Powell, R. (2014). Expressive Pedagogy: Practice/Theory, Theory/Practice. In G. Tate, A. R. Taggart, K. Schick, \& H. B. Hessler (Eds.), A Guide to Composition Pedagogies (2nd ed., pp. 111-127). Oxford University Press.

[3] Cobine, G. R. (1996). The Educational Value of Expressive Writing. ERIC Document Reproduction Service, 1-11.

[4] Flaherty, C. (2018). L'oeuf ou la Poule. Inside Higher Ed.

[5] Geisler, M. et al. (2007). Foreign Languages and Higher Education: New Structures for a Changed World: MLA Ad Hoc Committee on Foreign Languages. Profession, 234-245.

[6] Kim, Y. (2008). Effects of Expressive Writing among Bilinguals: Exploring Psychological Well-Being and Social Behaviour. British Journal of Health Psychology, 13(1), 43-47. https://pubmed.ncbi.nlm.nih.gov/18230230/

[7] Krashen, Stephen D. (1982). Principle and Practice in Second Language Acquisition. Pergamom Press.

[8] Mirhosseini, S.-A., \& Kianfar, R. (2019). Writing the World in a Foreign Language. Changing English, 26(1), 16-29.

[9] Paesani, K, \& Allen, H.W. (2012). Beyond the Language-Content Divide: Research on Advanced Foreign Language Instruction at the Postsecondary Level. Foreign Language Annals, 45(S1), s54-s75. https://onlinelibrary.wiley.com/doi/10.1111/j.19449720.2012.01179.x

[10] Villanueva, V. (2004). 'Memoria' Is a Friend of Ours: On the Discourse of Color. College English, 67(1), 9-19.

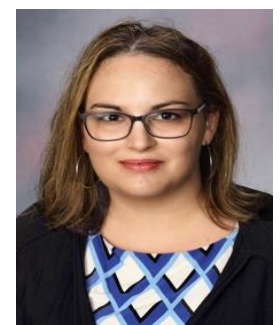

Elizabeth C. Langley holds a dual baccalaureate in International Affairs and Spanish / French (2005) as well as M.A. degrees in French (2009) and Spanish (2011) from Florida State University in Tallahassee, FL.

She also earned a Ph.D. in Romance Studies, Spanish Track (2019) from the University of Miami in Coral Gables, FL.

She has taught Spanish and French in secondary and higher education settings for more than ten years. She currently serves as Interim Chair and Assistant Professor of Spanish and French at Fort Hays State University in Hays, Kansas. Her previous work has appeared in The Latin Americanist and Teaching Haiti beyond Literature: Strategies for Creating New Narratives. Her research interests are broad and include second language acquisition and pedagogy, languages for the professions, and comparative literary and cultural studies of the Americas. 
Dr. Langley is a member of the American Council on the Teaching of Foreign Languages (ACTFL), the American Association of Teachers of Spanish and Portuguese (AATSP), the South Atlantic Modern Languages Association (SAMLA), the Midwest Association of Language Learning Technology (MWALLT), and the Kansas World Language Association (KSWLA). 